\title{
Aerobic nonylphenol degradation and nitro-nonylphenol formation by microbial cultures from sediments
}

\author{
Jasperien De Weert • Marc Viñas • Tim Grotenhuis • \\ Huub Rijnaarts • Alette Langenhoff
}

Received: 11 August 2009/Revised: 5 November 2009/Accepted: 30 November 2009/Published online: 31 December 2009

(C) The Author(s) 2009. This article is published with open access at Springerlink.com

\begin{abstract}
Nonylphenol (NP) is an estrogenic pollutant which is widely present in the aquatic environment. Biodegradation of NP can reduce the toxicological risk. In this study, aerobic biodegradation of NP in river sediment was investigated. The sediment used for the microcosm experiments was aged polluted with NP. The biodegradation of NP in the sediment occurred within 8 days with a lag phase of 2 days at $30^{\circ} \mathrm{C}$. During the biodegradation, nitro-nonylphenol metabolites were formed, which were further degraded to unknown compounds. The attached nitro-group originated from the ammonium in the medium. Five subsequent transfers were performed from original sediment and yielded a final stable population. In this NP-degrading culture, the microorganisms possibly involved in the biotransformation of NP to nitro-nonylphenol were related to ammonium-oxidizing bacteria. Besides the degradation of NP via nitro-nonylphenol, bacteria related to phenoldegrading species, which degrade phenol via ring cleavage, are abundantly present.
\end{abstract}

J. De Weert $(\bowtie) \cdot$ H. Rijnaarts $\cdot$ A. Langenhoff

Deltares, Princetonlaan 6,

3584 CB Utrecht, The Netherlands

e-mail: jasperien.deweert@deltares.nl

J. De Weert · T. Grotenhuis $\cdot$ H. Rijnaarts

Section of Environmental Technology, Wageningen University,

Bomenweg 2,

6703 HD Wageningen, The Netherlands

M. Viñas

GIRO Technological Center, Rambla Pompeu Fabra 1. E-08100

Mollet del Vallès,

Barcelona, Spain
Keywords Nonylphenol · Nitro-nonylphenol · Aerobic degradation - Nitrosomonas

\section{Introduction}

Nonylphenol (NP) is an estrogenic surfactant which is widely spread in the aquatic environment. Nonylphenols consist of a phenol group with a linear or a branched chain of nine carbon atoms. A technical mixture of branched nonylphenol (tNP) isomers is used for the production of nonylphenol polyethoxylates (NPEO; Wheeler et al. 1997; Thiele et al. 2004). This technical mixture does not contain linear NP (4-n-NP), and the linear form is, therefore, generally not present in natural samples. At anaerobic conditions in wastewater treatment plants, NPEO degrades partially to NP, which is a persistent end product in sewage sludges and the effluent of wastewater treatment plants (Stephanou and Giger 1982; Giger et al. 1984). When these NP-contaminated sludges and effluents are discharged, NP ends up in the environment as a pollutant.

Due to its chemical properties, NP adsorbs to sediments and accumulates in anaerobic sediments of various rivers such as the Llobregat river (Petrovic et al. 2002) and the Ebro river in Spain (Lacorte et al. 2006) and the Elbe river in the Czech Republic and Germany (Heemken et al. 2001). Nonylphenol can desorb from the sediment and re-enter the water phase where it can bioaccumulate in fishes and be harmful for other aquatic organisms (Tyler et al. 1998; Servos 1999; LeBlanc and Rider 2000; Snyder et al. 2001; Yang et al. 2005). Biodegradation of NP can reduce the toxicological risk of NP in the environment.

Under aerobic conditions, bacterial degradation of NP (branched and linear) has frequently been shown (Ekelund et al. 1993; Hesselsoe et al. 2001; Corvini et al. 2006a). 
However, anaerobic biodegradation of branched NP by bacteria is not observed so far. Only anaerobic biodegradation of linear NP has been described to occur in sediment from the Erren river in China under sulfate-reducing, nitrate-reducing, and methanogenic conditions (Chang et al. 2004). Aerobic NP-degrading bacterial strains are isolated from various environments. For example, Sphingomonas sp. TTNP3 and Sphingobium xenophagum Bayram, formerly known as Sphingomonas xenophaga Bayram, are isolated from wastewater treatment plants (Tanghe et al. 1999; Gabriel et al. 2005a). Stenotrophomonas sp. and Pseudomonas mandelii are isolated from polluted soils (Soares et al. 2003) and Sphingobium amiense, formerly known as Sphingomonas sp. YT (de Vries et al. 2001; Ushiba et al. 2003), from sediment. Most isolates are able to use NP as a sole carbon and energy source (Tanghe et al. 1999; Soares et al. 2003; Gabriel et al. 2005a), whereas some strains can only degrade NP cometabolically in the presence of yeast extract as carbon and energy source like S. amiense (de Vries et al. 2001).

Three possible bacterial degradation pathways of NP are mentioned in literature. One suggested pathway is the degradation of NP via a nonylphenol metabolite with a nitro-group at the ortho-position of the aromatic ring (Fig. 1). This metabolite was observed in the degradation experiments with soil and sewage sludge (Telscher et al. 2005) and in agricultural soils (Zhang et al. 2009). A second postulated pathway starts with the cleavage of the phenolic ring via the phenolic degradation pathway. This pathway is suggested for the biodegradation of NP by Pseudomonas spp., which was isolated from contaminated soil from a former industrial site (Soares et al. 2003). A third pathway of NP degradation starts with the hydroxylation of the C-4 atom of the aromatic ring to which the nonyl chain is attached, also called ipso-hydroxylation. This pathway is intensively studied in S. xenophagum Bayram and Sphingomonas sp. TTNP3. These strains were isolated from activated sludge from a municipal wastewater treatment plant and a lab-scale activated sludge reactor fed with NP, respectively (Tanghe et al. 1999; Gabriel et al. 2005a, b; Corvini et al. 2006b, 2007; Kohler et al. 2008).

This paper describes the aerobic biodegradation of the technical mixture of branched NP in NP-polluted river sediment. During the biodegradation process, the formation

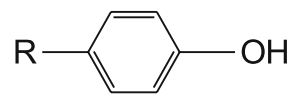

A

Fig. 1 Molecular structure of a nonylphenol and $\mathbf{b}$ ortho-nitro-nonylphenol of nitro-nonylphenol was observed. The origin of the nitrogroup was studied by using medium containing labeled ammonium nitrate $\left({ }^{15} \mathrm{NH}_{4} \mathrm{NO}_{3}\right.$ or $\left.\mathrm{NH}_{4}{ }^{15} \mathrm{NO}_{3}\right)$, and the possible involved microorganisms were identified by culture-independent approaches.

\section{Materials and methods}

Chemicals and stock solutions

Nonylphenol technical mixture (purity $>94 \%$ ) and linear NP (pestanal, purity $>99 \%$ ) were purchased from Riedel de Haën (Seelze, Germany). Labeled ${ }^{15} \mathrm{NH}_{4} \mathrm{NO}_{3}$ (98\% labeled) was ordered from Sigma-Aldrich (Zwijndrecht, The Netherlands) and $\mathrm{NH}_{4}{ }^{15} \mathrm{NO}_{3}$ (98\% labeled) from Isotech (Miamisburg, OH, USA). Solvents and chemicals were of the highest purity available and were used without further purification.

For the addition of tNP to the degradation experiments (22 $\mu \mathrm{M}$ of final concentration), a highly concentrated suspension of tNP $(3.5 \mathrm{mM})$ in water was prepared. UVsterilized tNP was used. During the UV-sterilization, no photo oxidized products or metabolites were formed as confirmed by gas chromatography-mass spectrometry (GCMS) analyses. Before using the suspension, the bottle with the suspension was heated at $60^{\circ} \mathrm{C}$ and shaken to homogenize the suspension. Homogeneity of the suspension was tested by analyzing four sets of triplicates by GCMS with solid-phase micro extraction (SPME), reaching $24 \%$ of standard deviation. By using this suspension, it was possible to add and re-add tNP as single carbon source in a small volume to batch experiments in a concentration of $22 \mu \mathrm{M}$ without the addition of an unwanted solvent, which may influence the biodegradation process.

Biodegradation experiments of tNP in slurries with originally polluted sediments

Nonylphenol polluted sediment was used for the biodegradation experiments and was collected in June 2005 from the Huerva river in Zaragoza (Spain; 41 $37^{\circ} 23^{\prime \prime} \mathrm{N}, 0^{\circ} 54^{\prime} 28^{\prime \prime} \mathrm{W}$ ), a tributary of the Ebro river. During the sampling, the temperature of the river water was $25.1^{\circ} \mathrm{C}$. Sediment was taken with stainless steel cores to $50 \mathrm{~cm}$ depth and transported on ice to the laboratory. In the laboratory, the sediment was sieved aerobically at mesh $<2 \mathrm{~mm}$ and stored at $4{ }^{\circ} \mathrm{C}$ until use. The sediment was polluted with $14 \pm 1.5 \mathrm{mg} / \mathrm{kg}$ dry weight sediment of branched NP isomers. The individual branched isomers were not identified, and linear NP was not present in the polluted sediment.

The aerobic degradation of the branched NP present in the polluted sediment was studied in $250 \mathrm{ml}$ serum bottles 
with $2 \pm 0.2 \mathrm{~g}$ dry weight tNP-polluted sediment and $50 \mathrm{ml}$ of aerobic medium, which results in $2.5 \pm 0.6 \mathrm{nmol} \mathrm{tNP}$ per milliliter slurry added with the sediment. No additional tNP was added to these batches. The headspace of the bottles $(200 \mathrm{ml})$ was filled with air. The aerobic medium was prepared as described in Tros et al. (1996) but without $\mathrm{Na}_{2} \mathrm{SeO}_{3} \cdot 5 \mathrm{H}_{2} \mathrm{O}$. The bottles were closed with a viton stopper with crimp cap and incubated horizontally shaken $(110 \mathrm{rpm})$ in the dark at $30^{\circ} \mathrm{C}$. These aerobic degradation experiments were performed in triplicate, and these batches were defined as the first generation (Scheme 1). Duplicate sterile controls were included, which were autoclaved for $1 \mathrm{~h}$ at $121^{\circ} \mathrm{C}$, followed by addition of $50 \mathrm{mg} / 1 \mathrm{HgCl}_{2}$ to prevent biological activity during the experiment. To follow the NP degradation, slurry samples $(200 \mu \mathrm{l})$ were taken regularly in duplicate from the batches and added to a capped $20 \mathrm{ml}$ headspace vial with $1.8 \mathrm{ml}$ MilliQ water with $7 \mathrm{mg} / \mathrm{l} \mathrm{HgCl}_{2}$ as described previously (de Weert et al. 2008).

\section{Transfers}

Transfers of the NP-degrading cultures were made and incubated at $30^{\circ} \mathrm{C}$ (Scheme 1). Each transfer was considered as a new generation and was prepared with fresh aerobic medium and $10 \%(v / v)$ of inoculum of the former generation. The second-generation batches were prepared with inoculum of the sediment slurry batches.

After two transfers, a tenfold dilution series (fourth generation) was performed to further enrich the NPdegrading population. The dilution series was carried out to a maximum dilution of $10^{10}$. The $10^{3}$ dilution of this fourth generation was used in further biodegradation experiments since this was the most enriched active incubation.
Transfers of this $10^{3}$ dilution were made in triplicate (fifth-generation batches coded as A.5, B.5, and C.5) in fresh aerobic medium with $10 \%(v / v)$ of inoculum to determine the degradation rate of the tNP. Degradation rate constants and half-life times were calculated from fifthgeneration batches by using first-order kinetics.

The sixth-generation batches (coded as A.6, B.6, and C.6) were used to investigate the degradation of the formed nitro-NP intermediates. After complete degradation of the added tNP in batch A.6 (15 days), $1 \mathrm{mM}$ tNP (=11.5 mg tNP; oversaturated) was added to this batch to study the effect of a high concentration of tNP on the microbial population.

For molecular analyses, samples from batch A.6 were taken before the addition of pure tNP ( $t=15$ days) and also after 17, 28, and 55 days. Samples for molecular analyses from batches B.6 and C.6 were taken after 6, 13, and 40 days of incubation.

\section{Metabolite formation}

To study the formation of the metabolites, degradation experiments were performed with tNP concentrations above the maximum water solubility. These experiments were encoded as experiment D. Batches with $2 \pm 0.2 \mathrm{~g}$ dry weight of the original sediment polluted with a mixture of branched NP isomers and $50 \mathrm{ml}$ of aerobic medium batches were prepared. The branched NP isomers in the sediment were completely degraded, after which $1 \mathrm{mM}$ UV-sterile pure tNP (=11.5 $\mathrm{mg}$ tNP) was added under sterile conditions. A sterile control was included, and the batches were incubated horizontally shaken $(110 \mathrm{rpm})$ in the dark at $30{ }^{\circ} \mathrm{C}$.

To be able to study the formation of an individual nitrononylphenol isomer, 4- $n$-NP was used as single NP isomer.
Scheme 1 Overview of transfers, dilution series, DNA samples, and clone libraries of samples with $11 \mu \mathrm{M}$ pure branched nonylphenol (tNP) and linear NP (4-n-NP) crystals

\begin{tabular}{|c|c|c|c|c|}
\hline $\begin{array}{l}1^{\text {st }} \\
\text { generation }\end{array}$ & $\begin{array}{l}2^{\text {nd }} \text { and } 3^{\text {rd }} \\
\text { generation }\end{array}$ & $\begin{array}{l}4^{\text {th }} \\
\text { generation }\end{array}$ & $\begin{array}{l}5^{\text {th }} \\
\text { generation }\end{array}$ & $\begin{array}{l}6^{\text {th }} \\
\text { generation }\end{array}$ \\
\hline $\begin{array}{l}\text { Sediment } \\
+ \text { medium }\end{array}$ & $\begin{array}{l}\text { Only medium } \\
\rightarrow 2 x \text { transfer- }\end{array}$ & Dilution series & $\begin{aligned} & \begin{array}{l}\text { Biodegradatio } \\
\text { rate }\end{array} \\
& \rightarrow \mathrm{A} .5 \\
& \rightarrow \mathrm{B} .5 \\
& \rightarrow \mathrm{C} .5 \\
& 6 \mu \mathrm{M} \mathrm{tNP}\end{aligned}$ & $\begin{aligned} \rightarrow \text { A.6 DNA; } t=15,17,28 \text { and } 55 \mathrm{~d} \\
\text { Addition pure } t N P: t=15 \mathrm{~d} \\
\text { Clone library; } \mathrm{t}=15 \mathrm{~d} \\
\rightarrow \text { B.6 DNA; } \mathrm{t}=6,13 \text { and } 40 \mathrm{~d} \\
\rightarrow \text { C.6 DNA; } t=6,13 \text { and } 40 \mathrm{~d} \\
15 \mu \mathrm{M} \text { tNP }\end{aligned}$ \\
\hline $\begin{array}{l}1^{\text {st }} \\
\text { generation }\end{array}$ & $\begin{array}{l}2^{\text {nd }} \text { and } 3^{\text {rd }} \\
\text { generation }\end{array}$ & $\begin{array}{l}4^{\text {th }} \\
\text { generation }\end{array}$ & & \\
\hline $\begin{array}{l}\text { Sediment } \\
+ \text { medium }\end{array}$ & $\begin{array}{l}\text { Only medium } \\
\rightarrow 2 x \text { transfer- } \\
\text { Pure tNP } \\
(1 \mathrm{mM})\end{array}$ & 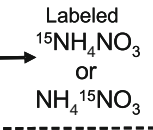 & & $\begin{array}{l}4 \text { DNA; } t=51 d \\
\text { Clone library; } t=51 d\end{array}$ \\
\hline & $\begin{array}{l}2^{\text {nd }} \\
\text { generation }\end{array}$ & $\begin{array}{l}3^{\text {th }} \\
\text { generation }\end{array}$ & & \\
\hline & $\overrightarrow{4-n-N P \text { crystals }} \stackrel{\text { transfer }}{-}$ & $\begin{array}{r}\operatorname{trans} \\
4-n-\mathrm{NP} \mathrm{C}\end{array}$ & als & mass weight analysis \\
\hline
\end{tabular}


Batches were incubated in duplicate with $4-n$-NP in concentrations above the maximum water solubility $(5 \mathrm{mg} / \mathrm{l})$. Inoculum $(10 \%, v / v)$ was used from the firstgeneration tNP-degrading slurry batch (Scheme 1).

All the batches were sampled regularly and were analyzed by GC-MS. Per analyzed sample, $200 \mu$ slurry was taken from the bottles and added to a capped 20-ml headspace vial with $1.8 \mathrm{ml}$ MilliQ water with $7 \mathrm{mg} / 1 \mathrm{HgCl}_{2}$ as described in Weert et al. (2008).

Degradation experiments of tNP with ${ }^{15} \mathrm{~N}$-labeled $\mathrm{NH}_{4} \mathrm{NO}_{3}$

Inoculum from the third-generation batch (Scheme 1) was used for the degradation batches in medium with labeled ${ }^{15} \mathrm{NH}_{4} \mathrm{NO}_{3}$ or $\mathrm{NH}_{4}{ }^{15} \mathrm{NO}_{3}$ to study the origin of the incorporated $\mathrm{NO}_{2}$-group of the formed intermediate. Therefore, batches were prepared in triplicate with $50 \mathrm{ml}$ aerobic medium with either $12.5 \mathrm{mM}{ }^{15} \mathrm{NH}_{4} \mathrm{NO}_{3}$ or $\mathrm{NH}_{4}{ }^{15} \mathrm{NO}_{3}$ and $1 \mathrm{mM}$ tNP (above saturation) and 10\% $(v / v)$ of inoculum. The batches were incubated horizontally shaken $(110 \mathrm{rpm})$ in the dark at $30^{\circ} \mathrm{C}$. Samples were collected for GC-MS analysis at different time intervals to follow the formation of intermediates of the degradation of tNP. Individual isomers were not tested with labeled $\mathrm{NH}_{4} \mathrm{NO}_{3}$. Samples for molecular analyses were taken after 51 days of incubation from one of these fourth-generation batches grown with ${ }^{15} \mathrm{NH}_{4} \mathrm{NO}_{3}$ (batch coded as D.4).

\section{Chemical analyses}

To analyze the concentration of tNP and the formation of metabolites in the batches, the collected liquid samples in the 20-ml headspace vials were measured by GC-MS with SPME injections. The NP and the metabolites were extracted with an $85-\mu \mathrm{m}$ polyacrylate SPME fiber from the headspace of the samples and analyzed by GC-MS as described in Weert et al. (2008).

Accurate mass weight analysis was used to identify the formed metabolites with a nitro-group. The GC-MS chromatograms suggested that the incorporated $\mathrm{NO}_{2}$-group was attached to the phenolic ring and not to the chain. Therefore, the nitro-phenol metabolite from the thirdgeneration batch with the single isomer $4-n$-NP was extracted instead of the group of nitro-metabolites that were formed when tNP was used, since only one single metabolite isomer could be identified with accurate mass weight analysis. The metabolite was extracted from $15 \mathrm{ml}$ medium with $10 \mathrm{ml}$ dichloromethane and hexane $(1: 1)$ by horizontally shaking $(110 \mathrm{rpm})$ for $2 \mathrm{~h}$ at $30^{\circ} \mathrm{C}$. The dichloromethane/hexane was completely evaporated; the extracted metabolite was resuspended in $40 \mu$ l dichloromethane and analyzed via direct insert probe mass analysis on a Finnigan MAT95 mass spectrometer. An amount of
$2 \mu \mathrm{l}$ sample was loaded into the mass spectrometer. The analysis started at room temperature, and the temperature of the sample was increased in steps of $10^{\circ} \mathrm{C}$ until enough sample evaporated for analysis. Data were acquired in the electron impact mode $(70 \mathrm{eV})$ at a resolution of 5,400 , scanning range $m / z 24-600$ at $2 \mathrm{~s}$ per decade. Molecular ion peak $m / z 265$ was used for accurate mass weight analyses.

DNA extraction and polymerase chain reaction

To extract the DNA from the batches, $5 \mathrm{ml}$ of a different time period of the sixth-generation batches A.6, B.6, and C.6 was filtrated through a $0.2-\mu \mathrm{m}$ pore size cellulose acetate filter (Whatman GmbH, Dassel, Germany). Material that was attached to the viton rubber stopper from the fourth-generation batch D.4 was used as well. After filtration, DNA was extracted by using a BIO101 Systems Fast DNA ${ }^{\circledR}$ Kit for Soil (Qbiogene, Inc., CA, USA) according to the manufacturer's instructions. Bead-beat step was modified from 30 to $45 \mathrm{~s}$. The extracted DNA was stored at $-20^{\circ} \mathrm{C}$ until further analysis.

Nested polymerase chain reaction (PCR) approach encompassing two PCR steps was performed with the extracted DNA. The first PCR on the DNA samples was performed to amplify the complete $16 \mathrm{~S}$ rRNA genes with the bacterial primer mixture $\mathrm{fD} 1 / \mathrm{fD} 2$ and $\mathrm{rP} 1 / \mathrm{rP} 2$ as based on the method described by Weisburg et al. (1991). Tenfold diluted PCR amplicons of the complete 16S rRNA genes were used to carry out a clone library. Amplifications were performed with 1.25 U Takara Ex Taq DNA polymerase (Takara Bio, Otsu, Shiga, Japan).

For the denaturing gradient gel electrophoresis (DGGE), direct amplification of the DNA with the F341-GC and R534 primers was not possible. Therefore, a nested-PCR approach was performed. These nested amplifications were performed with $0.4 \mathrm{U}$ Taq-polymerase (Fermentas International, Inc., Burlington, Canada), and a tenfold diluted PCR amplicon from first PCR was amplified in this nested step (second PCR reaction). The primers F341-GC, including a GC-clamp and R534, were used in the nested PCR based on the method described by Yu and Morrison (2004).

\section{Denaturing gradient gel electrophoresis}

A DGGE was performed based on the method described by $\mathrm{Yu}$ and Morrison (2004). Approximately $400 \mathrm{ng}$ of nestedPCR product $(25 \mu \mathrm{l})$ was loaded on an $8 \%(w / v)$ polyacrylamide gel with a denaturing gradient of $30 \%$ to $70 \%$ denaturant using a Dcode ${ }^{\mathrm{TM}}$ Universal Mutation Detection System (Bio-Rad) at $100 \mathrm{~V}$ at $60^{\circ} \mathrm{C}$ for $16 \mathrm{~h}$. The gels were stained for 45 min with SybrGold (Molecular Probes, Inc., Eugene, OR, USA) in $20 \mathrm{ml}$ of TAE and viewed under UV light. DGGE bands were processed using 
Quantity-one version 4.6.2 image analysis software (Bio-Rad Laboratories, Hercules, CA, USA) and corrected manually when needed. After normalization of the gels, bands with the relative peak area intensity above $1 \%$ were included in further analyses and were digitalized and analyzed.

Bacterial diversity, based on DGGE gel analysis, was assessed by using Shannon-Weaver diversity index $\left(H^{\prime}=\right.$ $-\sum P_{i} \log P_{i}$ ) (Shannon and Weaver 1949). $P_{i}$ is the relative peak intensity of a DGGE band, calculated as $P_{i}=n_{i} / N$, where $n_{i}$ is the peak area of the band and $N$ the sum of all the peak areas in a DGGE lane. Furthermore, a covariance principal component analysis (PCA) was performed on band type and peak height with the Excel application StatistiXL, version 1.8 , to consider possible shifts and similarities in microbial populations during the incubation of batches A.6, B.6, C.6, and D.4.

\section{Cloning and sequencing}

Clone libraries of 16S rRNA genes were constructed from the DNA of batch A.6 at 15 days, cultured with $15 \mu \mathrm{M}$ tNP and of batch D.4 cultured with $1 \mathrm{mM}$ tNP (saturated). The PCR amplicons of the 16S rRNA genes were purified with the QIA Quick ${ }^{\circledR}$ PCR purification kit (Qiagen, Hilden, Germany). Almost complete 16S rRNA gene fragments were cloned by using the TOPO-TA cloning Kit (Invitrogen, Carlsbad, CA, USA) according to the manufacturer's protocol. The plasmids were purified with the Qiagen Qia prep ${ }^{\circledR}$ spin mini prep kit and sent for sequencing to Eurofins MWG Operon (Ebersberg, Germany) with M13 uni (-21) sequencing primer. Sequences were inspected for ambiguous base assignments and were compared with sequences deposited in public accessible databases using the NCBI BLAST search tool at htpp://www.ncbi.nlm.nih.gov/blast. Alignment of the sequences was done by Clustralw on line software at http:// www.ebi.ac.uk/tools/clustralw2.

\section{GenBank accession numbers}

The 16S rRNA gene nucleotide sequences determined in this study have been deposited into the GenBank database under accession numbers FJ591135-FJ591150, FJ609321FJ609385, and FJ626783-FJ626794. If sequences were identical, the longest sequence was submitted.

\section{Results}

Nonylphenol degradation

The biodegradation of the mixture of branched NP isomers that was present in the polluted sediment (first-generation batches) started after a lag phase of 2 days. Within 8 days,
$95 \%(3.3 \pm 0.4 \mathrm{nmol} / \mathrm{ml}$ slurry $)$ of the original present $\mathrm{NP}$ isomers were biodegraded (data not shown). The half-life time of tNP in the sediment was $1.5 \pm 0.4$ day. The higher present amount of NP in the slurry compared to amount mentioned in the "Materials and methods" section is because the NP was present in the used sediment and not additionally added. The sediment was heterogeneous polluted with NP, even after making the sediment as homogenous as possible.

In the batches of the $10^{3}$ diluted fifth generation, tNP was added, and a decrease in tNP concentration in batches A.5, B.5, and C.5 was observed from $t=0$ (Fig. 2). The decrease during these first days was due to other processes than degradation by microorganisms, since this decrease was also observed in the sterile control. This abiotic decrease can be due to adsorption to the glassware and the viton stopper, since it is known that NP has the tendency to adsorb to surfaces (Hou et al. 2006; Navarro et al. 2009). In the fifth-generation batch A.5, the biodegradation started after 1 day, and within less than 12 days, $3 \mu \mathrm{M}$ tNP was degraded. The biodegradation in the fifthgeneration batches B.5 and C.5 started after 5 days of incubation, and $4 \mu \mathrm{M}$ tNP was biodegraded within 10 and 11 days, respectively. The half-life time of tNP in these transfers varied from 4 to 5 days, although the data are limited for calculating the half-life times.

\section{Metabolite formation}

Addition of pure tNP at a concentration of $1 \mathrm{mM}$ (above saturation) to biodegradation batches resulted in the formation of a group of metabolites as seen in the GCMS chromatogram (Fig. 3). The metabolites were not present at the start of the experiment and were not observed in the sterile control indicating that these metabolites were formed during the degradation of NP. The peak pattern of tNP in the GC-MS chromatogram was seen between retention times 7.5 and $8.5 \mathrm{~min}$ (Fig. 3). The pattern

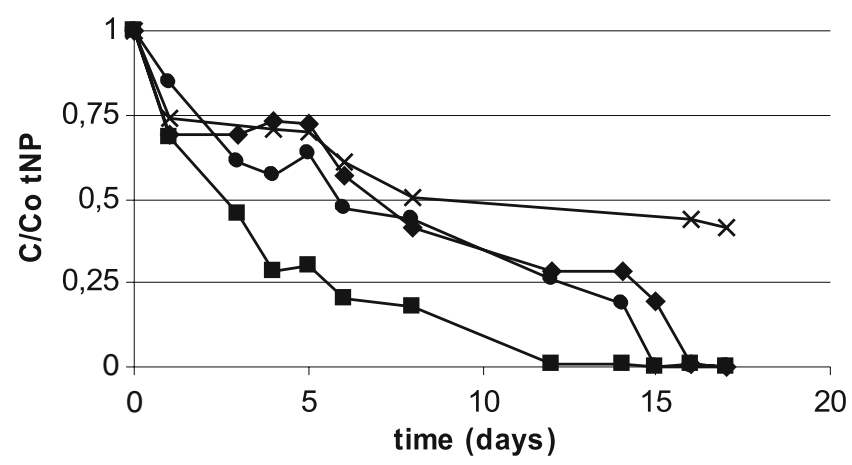

Fig. 2 Degradation of branched NP ( $\mathrm{tNP})$ as $\mathrm{C} / \mathrm{C}_{0}$ in fifth-generation transfers from Huerva River sediment, Spain. In triplicate, closed squares A.5, closed circles B.5, closed diamonds C.5, and ex-mark sterile control 
Fig. 3 GC-MS chromatogram of tNP and nitro-nonylphenol metabolite, including mass spectra

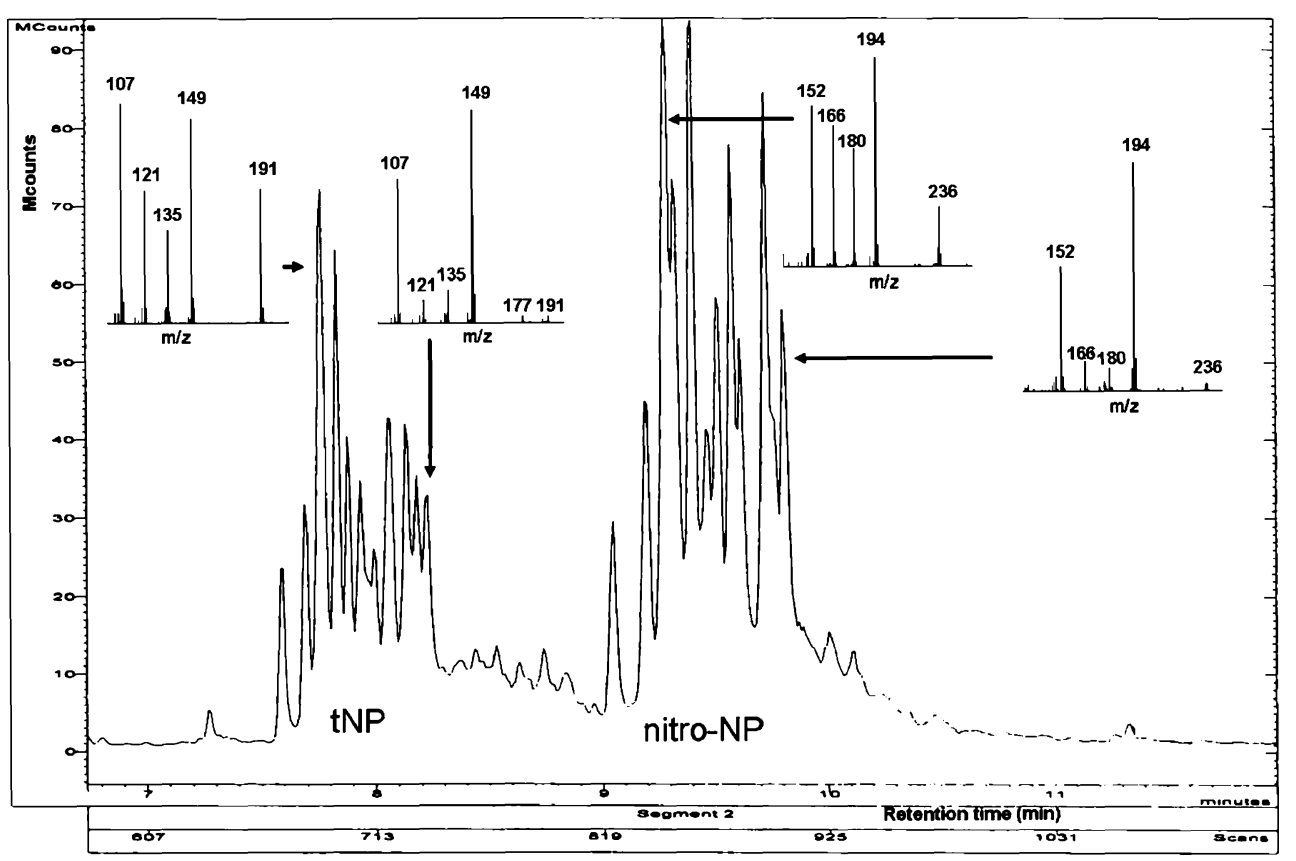

consists of several peaks since tNP is a mixture of branched NP isomers. The peak pattern of the formed group of metabolites was seen between 9 and $10 \mathrm{~min}$ and showed the same peak pattern as the tNP. The fragmentation pattern of tNP contains ions of $m / z 107,121,135,149$, and 191, whereas the fragmentation patterns of the metabolites showed ions of $m / z 152,166,180,194$, and 236, indicating a mass shift of $45 \mathrm{~m} / \mathrm{z}$. The same mass shift of $45 \mathrm{~m} / \mathrm{z}$ was observed in the batches growing on 4- $n$-NP. An estimation of the metabolite concentration was not made because the response of the group of metabolites in the GC-MS was unknown.

The similarity of the chromatogram pattern of the tNP and the group of metabolites, as well as the same mass shift of 4- $n$-NP, indicated the substitution of a hydrogen atom by a nitro-group at the phenolic ring (Posthumus 2008, Department of Organic Chemistry, Wageningen University, the Netherlands, personal communication). This was confirmed by the results of the accurate mass weight analysis in extract of the sample of the 4- $n$-NP degradation. The observed mass spectrum contained $\mathrm{m} / \mathrm{z} 43 \quad(11 \%$ relative intensity), 57 (9), 106 (8), 135 (11), 152 (100), and 265 (56), which was in agreement with a 2- or 3-nitro4-nonylphenol. Nuclear magnetic resonance analysis could not be performed to identify the position of the nitro-group in the molecular structure, as the concentration of the metabolite in the extract was too low.

Incubations with tNP above the maximum solubility and labeled ${ }^{15} \mathrm{NH}_{4} \mathrm{NO}_{3}$ or $\mathrm{NH}_{4}{ }^{15} \mathrm{NO}_{3}$ medium were performed to investigate the origin of the nitro-group. The nitro-group attached to the NP in the batches with labeled ${ }^{15} \mathrm{NH}_{4} \mathrm{NO}_{3}$ gave a shift in mass weight of $46 \mathrm{~m} / \mathrm{z}$, whereas the formed metabolite in the incubates with labeled $\mathrm{NH}_{4}{ }^{15} \mathrm{NO}_{3}$ showed the earlier observed shift in mass weight of $45 \mathrm{~m} / \mathrm{z}$. The mass weight shift of $46 \mathrm{~m} / \mathrm{z}$ indicated that a labeled N-atom was attached to the NP. Because the mass shift of $46 \mathrm{~m} / \mathrm{z}$ was only observed with labeled ammonia, this demonstrates that the attached nitro-group in the metabolites originated from the ammonium in the medium via the formation of nitrite and not of nitrate. If the nitro-group had originated from the nitrate, a mass shift of $46 \mathrm{~m} / \mathrm{z}$ would also have been observed in the batches with labeled nitrate. An abiotic reaction between NP and added nitrite $(12.5 \mathrm{mM})$, resulting in the formation of nitro-nonylphenol, was not observed in the first 4 weeks of incubation. More prolonged abiotic incubation showed the formation of nitrononylphenol (data not shown). In our batches, the formation of nitro-nonylphenol was already observed after 10 days of incubation. This indicates that the production of nitro-NP in our batches appears to be a biological process and can also be formed in low amounts, after longer periods of incubation, through abiotic mechanisms.

Abiotic incubations with tNP above the maximum solubility and nitrite $(12.5 \mathrm{mM})$ under abiotic conditions did not show the formation of nitro-nonylphenol within 4 weeks of incubation. More prolonged abiotic incubation showed the formation of nitro-nonylphenol (data not shown).

The nitro-nonylphenol metabolites accumulated in the batches with tNP concentrations above the maximum water solubility. Nitro-nonylphenol was also detected in the sixthgeneration batches A.6, B.6, and C.6 cultured with only $11 \mu \mathrm{M}$ tNP. Figure 4 shows this formation in batch A.6, before the addition of $1 \mathrm{mM}$ tNP (above saturation) at $t=$ 15, and of batch B.6. Nitro-nonylphenol was already produced during the first 10 days in batch A.6, followed by a decrease in concentration indicating that the metabolite 


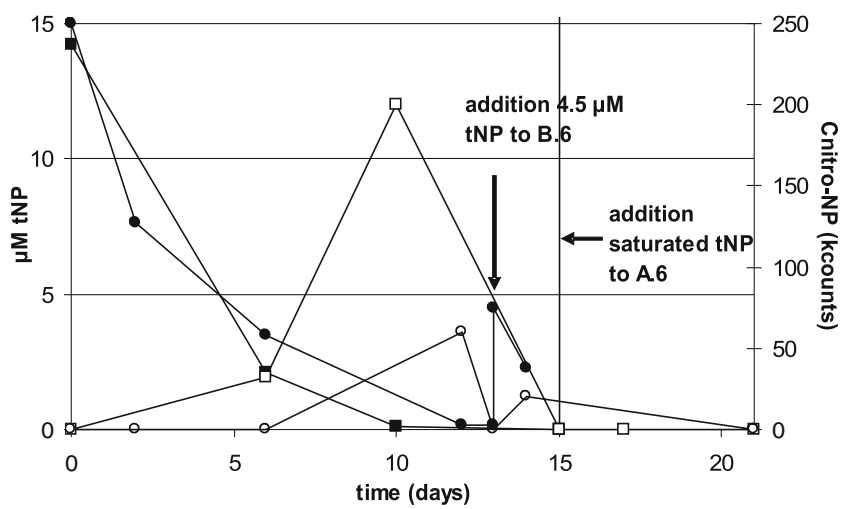

Fig. 4 Concentration profiles during branched NP (tNP) degradation in a batch system of the sixth-generation transfer. tNP in micromolar (tNP; left Y-axis, closed symbols) and nitro-nonylphenol in $k$ counts (right Y-axis, open symbols). Closed and open squares A.6, closed and open circles B.6

was further degraded. After the addition of $1 \mathrm{mM}$ tNP to this batch, no nitro-nonylphenol metabolites were measured in this batch. In batch B.6, nitro-nonylphenol was produced between the sixth and 12th days of incubation. At $t=13$, the concentrations of tNP and the nitro-nonylphenol decreased below the detection limit $(18 \mathrm{nM})$. After re-addition of $4.5 \mu \mathrm{M}$ tNP at $t=13$, an increase of nitro-nonylphenol was observed again at $t=14$ followed by a decrease, again indicating the biodegradability of the formed nitrononylphenol. No further metabolites were observed from further degradation of the nitro-nonylphenol by our used GC-MS method.

\section{Microbial diversity}

The effect of the presence of $11 \mu \mathrm{M}$ tNP or tNP in a concentration above the maximum solubility on the microbial population was analyzed by DGGE. The band patterns in the DGGE of the four DNA samples at different times during the incubation from the sixth-generation batch A.6 contained 15 to 18 DGGE bands (Fig. 5). The Shannon-Weaver diversity index obtained from the DGGE profiles varied between 1.09 and 1.10, indicating that the diversity did not change during the incubation. Also, no change in diversity was observed after the addition of a tNP concentration above the maximum solubility at day 15 , and the population remained stable. The DGGE patterns of the samples at different times of the sixth generation, batches B.6 and C.6, cultured with only $11 \mu \mathrm{M} \mathrm{NP}$, contained both 16 to 18 bands and looked similar to the patterns of the samples of batch A.6. The Shannon-Weaver diversity index B. 6 and C. 6 ranged from 1.08 to 1.12 , respectively. This indicated that the microbial diversity of batches B.6 and C. 6 did not change either during the incubation of 40 days. This was confirmed by PCA (Fig. 6). In fact, the DGGE profiles of the batches A.6, B.6, and C.6 had almost the

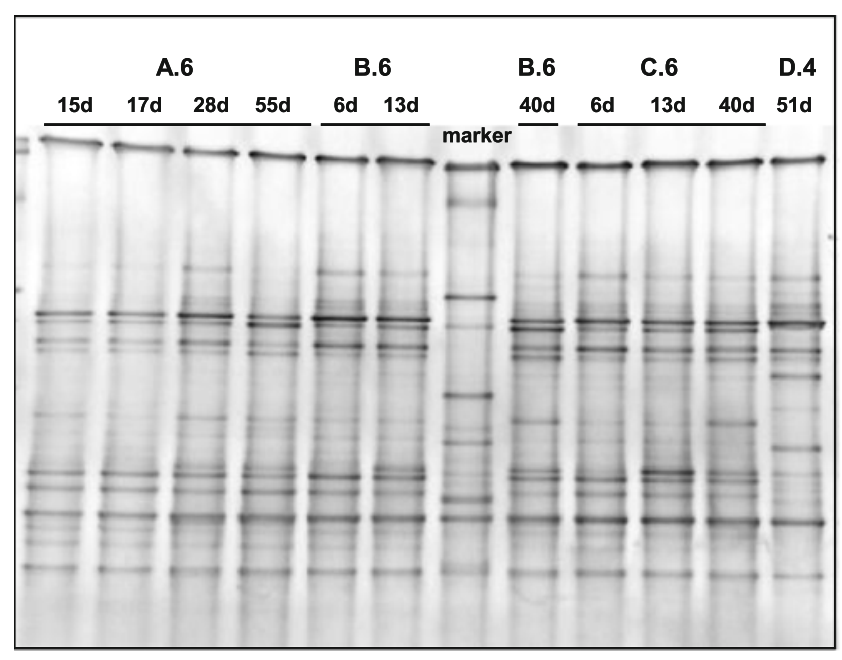

Fig. 5 Denaturing gradient gel electrophoresis of sixth-generation transfers A. 6 cultured with $11 \mu \mathrm{M}$ tNP till $t=15$ days and thereafter with $1 \mathrm{mM}$ tNP, B.6 and C.6 incubated with $11 \mu \mathrm{M} \mathrm{tNP}$, and fourthgeneration transfer D. 4 incubated with $1 \mathrm{mM}$ tNP at different time intervals

same PC1 and PC2 value in the scatter plot. During the incubation of batches A.6, B.6, and C.6, no changes were observed in the PC1 and PC2, indicating only a small change in the microbial diversity.

The DGGE pattern of the sample of batch D.4, which is a fourth-generation transfer cultured with $1 \mathrm{mM}$ tNP (above saturation), contained 14 bands. The Shannon-Weaver index for microbial diversity of sample of D.4 was 1.05 . This indicates that the microbial diversity in sample D.4 was less than in the samples of batches A.6 to C.6. The pattern showed similarities with the patterns of the samples of batches A.6 to C.6, but there were also some different dominating bands present. The PCA results of the DGGE profiles (Fig. 6) show that the data point of sample D.4 did not cluster with the results of batches A.6, B.6, and C.6.

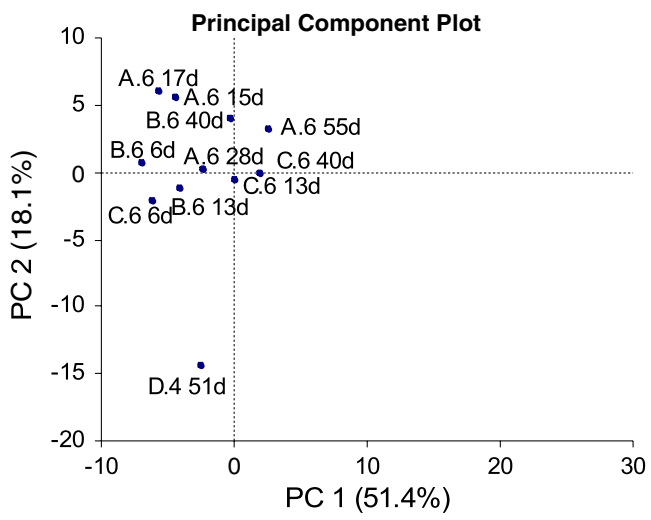

Fig. 6 Principal component analysis scatter plot of DGGE profiles (Fig. 6) of sixth-generation transfers A.6 cultured with $11 \mu \mathrm{M}$ tNP till $t=15$ days and thereafter with $1 \mathrm{mM} \mathrm{tNP}$, B. 6 and C.6 incubated with $11 \mu \mathrm{M}$ tNP, and fourth-generation transfer D.4 incubated with $1 \mathrm{mM}$ tNP at different time intervals 
This indicates that incubation with a tNP concentration above maximum solubility gives a different microbial population compared to incubation with $11 \mu \mathrm{M}$ tNP concentration.

\section{Microbial population composition}

As the microbial composition of A.6 did not change during the incubation time and was similar to batches B.6 and C.6, a clone library was made of batch A.6. The DNA extract from $t=15$ days was used when nitro-nonylphenol was formed. A second clone library was made from batch D.4 at $t=55$ days, which showed a different microbial composition on the DGGE pattern. Batch D. 4 was cultured with $1 \mathrm{mM}$ NP, whereas A.6, B.6, and C.6 were cultured with $15 \mu \mathrm{M}$ tNP. Respectively, 70 and 49 clones were obtained from batches A.6 and D.4 (Table 1). The most dominant clones of A.6 were related to Nitrosomonas genus (36 out of 70 clones), which are ammonium-oxidizing bacteria (Stein et al. 2007). Of these 36 clones, 18 were closely related to Nitrosomonas euthropha (GenBank accession number AY123795) with a maximum 16S rRNA gene identity of 91-100\%. Another 16 clones were closely related to $N$. euthropha C91 with a maximum identity of $99 \%$. Alignment of the sequences of $N$. euthropha (GenBank accession number AY123795) and N. euthropha C91 showed a 99\% similarity between these two strains. In the clone library of batch D.4, clones were also identified that are related to $N$. euthropha (two out of 49) and N. euthropha C91 (four out of 49); however, they were less abundantly present than in the clone library of batch A.6. Three clones were related to Nitrosomonas sp. GC22 with a similarity of $96-99 \%$.

Clones related to the sequence of Beta proteobacterium C14 JRPA-2007 (eight out of 70 clones) were also dominantly present in the clone library of batch A6. B. proteobacterium C14 JRPA-2007 sequence belongs to the Alcaligenacea family and is closely related to Alcaligenes sp. Ic4, a 3-chlorobenzoate degrading microorganism (Krooneman et al. 1996). Clones (four out of 49 clones) related to B. proteobacterium C14 JRPA-2007 were also present in the clone library of batch D.4.

The most dominating clones in the clone library from batch D. 4 belonged to the family Comamonadacea (28 out of 49 clones). Thirteen clones were closely related to Acidovorax sp. PD-10 (92-99\% similarity) and 11 clones to Alicycliphillus sp. R-24604 (96-99\% similarity). Acidovorax sp. PD-10 is closely related to the species Acidovorax avenae isolate $\mathrm{C} 1$ (AF508114), which is a phenol-degrading, nitrate-reducing bacterium (Baek et al. 2003). Alignment of the sequences of Alicycliphillus sp. R-24604 (AM084015) and $A$. avenae isolate C1 (AB195159) gave 99\% similarity of these two strains. This indicates that Alicycliphillus sp. $\mathrm{R}-24604$ is very closely related to $A$. avenae isolate $\mathrm{C} 1$ as well. Clones related to Acidovorax sp. PD-10 and Alicycliphillus sp. R-24604 were also identified in the clone library of batch A.6 and were less dominantly present than in the clone library of batch D.4.

\section{Discussion}

The mixture of branched NP isomers that were present in the polluted sediment can be biodegraded under aerobic conditions by the autochthon microorganisms. The biodegradation of NP in our sediment was much faster compared to the aerobic degradation of NP in sediment from the Erren river in China (Yuan et al. 2004). Within 8 days, approximately $4.5 \mu \mathrm{M}$ NP was biodegraded, whereas biodegradation of $9 \mathrm{nM}$ in Erren river sediment took 84 days. Adaptation of the Erren sediment to NP degradation increased the biodegradation to 28 days. Faster biodegradation in our sediment is due to adaptation of the bacteria to NP because our used sediment was already polluted with NP.

Subsequent transfers of the microbial population from our sediment enlarged the lag phase compared to the first generation and increased the half-life time of tNP. Often, transfers of a culture result in the enrichment of the involved microorganisms in the degradation process and a decrease of the half-life time. Due to our transfers, the originally present sediment with some river water was diluted out, and the fifth-generation batches hardly contained any sediment. This diluting out of the sediment might play a role for the bacteria, either as carrier material of for essential nutrients.

The biodegradation by microorganisms in the sediment of NP, both branched and linear NP, occurs via the formation of a nitro-nonylphenol metabolite. The attached $\mathrm{NO}_{2}$-group in the formed nitro-nonylphenol originates from ammonium and is a biotic process in our experiments. The formation of nitro-nonylphenol, with the nitro-group attached to the phenolic ring, was also observed in biodegradation studies with agricultural soils (Zhang et al. 2009) and a mixture of agricultural soils with sewage sludge (Telscher et al. 2005; Zhang et al. 2009). This indicates that the formation of nitro-nonylphenol is relevant in the biodegradation of tNP. The formed nitro-nonylphenol in our experiments was further degraded, which was also observed in agricultural soils (Zhang et al. 2009). In these soils, the formed nitro-nonylphenol was not completely degraded; $13 \%$ of the initial applied NP remained in the sediment as a nitro-metabolite. In our experiments, the nitro-nonylphenol was only completely degraded when $11 \mu \mathrm{M}$ tNP was applied. Higher concentrations $(1 \mathrm{mM})$ led to accumulation of the nitro-metabolites. Despite this incomplete degradation, biodegradation of NP in this 
Table 1 Phylogenetic affiliations and frequencies of bacterial 16S rRNA gene clones in clone library of a sixth-generation transfer cultured with $11 \mu \mathrm{M}$ branched nonylphenol (A.6) and the fourth-generation transfer cultured with a NP concentration above maximum water solubility (D.4)

\begin{tabular}{|c|c|c|c|c|c|c|}
\hline Phylogenetic group & $\begin{array}{l}\text { Closest related organism GenBank } \\
\text { (accession number) }\end{array}$ & Accession number & $\begin{array}{l}\text { Similarity } \\
(\%)\end{array}$ & $\begin{array}{l}\text { Number } \\
\text { of clones }\end{array}$ & $\begin{array}{l}\text { Similarity } \\
(\%)\end{array}$ & $\begin{array}{l}\text { Number } \\
\text { of clones }\end{array}$ \\
\hline Alcaligenaceae $(\beta)$ & $\begin{array}{l}\text { Beta proteobacterium C14 JRPA-2007 } \\
\text { (EF599312) }\end{array}$ & $\begin{array}{l}\text { FJ609349-FJ609350, } \\
\text { FJ609379-FJ609381, } \\
\text { FJ626785, FJ626786 }\end{array}$ & $97-99$ & 8 & $95-99$ & 4 \\
\hline \multirow{2}{*}{$\begin{array}{l}\text { Bradyrhizobiaceae; } \\
\text { Bradyrhizobium } \\
(\alpha)\end{array}$} & $\begin{array}{l}\text { Bradyrhizobium japonicum strain HMJ-03 } \\
\text { (EU481826) }\end{array}$ & FJ609338-FJ609339 & $98-99$ & 3 & - & - \\
\hline & Bradyrhizobium sp. MOB-4 (EF681762) & FJ609336-FJ609337 & 99 & 3 & - & - \\
\hline $\begin{array}{l}\text { Bradyrhizobiaceae; } \\
\text { Afipia }(\alpha)\end{array}$ & Afipia felis (AF338177) & FJ609333-FJ609335 & $96-99$ & 4 & - & - \\
\hline $\begin{array}{l}\text { Bradyrhizobiaceae; } \\
\text { Oligotropha }(\alpha)\end{array}$ & $\begin{array}{l}\text { Uncultured bacterium clone RO229 } \\
\text { (AB099660) }\end{array}$ & FJ609351 & 95 & 1 & - & - \\
\hline $\begin{array}{l}\text { Comamonadaceae } \\
(\beta)\end{array}$ & Acidovorax sp. PD-10 (AB195159) & $\begin{array}{l}\text { FJ609345-FJ609348, } \\
\text { FJ609356-FJ609363, } \\
\text { FJ626783 }\end{array}$ & $96-99$ & 4 & $92-99$ & 10 \\
\hline \multirow[t]{3}{*}{$\begin{array}{l}\text { Comamonadaceae; } \\
\text { Alicycliphillus }(\beta)\end{array}$} & Alicycliphilus sp. R-24604 (AM084015) & $\begin{array}{l}\text { FJ609353-FJ609354, } \\
\text { FJ626790-FJ626794, } \\
\text { FJ626787 }\end{array}$ & $97-99$ & 2 & $95-99$ & 11 \\
\hline & $\begin{array}{l}\text { Uncultured bacterium clone 181up } \\
\text { (AY212633) }\end{array}$ & $\begin{array}{l}\text { FJ609384-FJ609385, } \\
\text { FJ626783, FJ626784 }\end{array}$ & - & - & $96-97$ & 2 \\
\hline & $\begin{array}{l}\text { Uncultured bacterium clone EC2-2 } \\
\text { (EU741793) }\end{array}$ & FJ609369-FJ609370 & - & - & $94-99$ & 2 \\
\hline $\begin{array}{r}\text { Micrococcaceae } \\
\text { (Acetinobacter) }\end{array}$ & $\begin{array}{l}\text { Uncultured bacterium clone M40C11 } \\
\text { (EU331390) }\end{array}$ & FJ609352 & 91 & 1 & - & - \\
\hline \multirow[t]{4}{*}{$\begin{array}{l}\text { Nitrosomonadaceae } \\
(\beta)\end{array}$} & Nitrosomonas eutropha (AY123795) & $\begin{array}{l}\text { FJ591139-FJ591150, } \\
\text { FJ609364-FJ607368 }\end{array}$ & $91-100$ & 18 & $93-99$ & 2 \\
\hline & Nitrosomonas eutropha C91 (CP000450) & $\begin{array}{l}\text { FJ609322-FJ609331, } \\
\text { FJ609371-FJ609373 }\end{array}$ & 99 & 16 & $98-99$ & 4 \\
\hline & Nitrosomonas sp. GH22 (AB000701) & FJ609321 & 94 & 1 & $96-99$ & 3 \\
\hline & Nitrosomonas sp. clone 74 (AJ224410) & FJ609332 & 90 & 1 & - & - \\
\hline Rhodocyclaceae $(\beta)$ & Uncultured Azoarcus sp. (AY098637) & FJ609355 & - & - & 97 & 1 \\
\hline \multirow[t]{3}{*}{$\begin{array}{l}\text { Rhodocyclaceae; } \\
\text { Thauera }(\beta)\end{array}$} & $\begin{array}{l}\text { Uncultured bacterium clone 189up } \\
\text { (AY212641) }\end{array}$ & FJ609374 & - & - & 95 & 2 \\
\hline & Thauera sp. R-26885 (AM084104) & FJ609375 & - & - & 97 & 1 \\
\hline & $\begin{array}{l}\text { Uncultured bacterium clone: nsmpV06 } \\
\text { (AB210048) }\end{array}$ & FJ609376 & - & - & 96 & 1 \\
\hline \multirow[t]{2}{*}{ Rhodospirillaceae $(\alpha)$} & $\begin{array}{l}\text { Uncultured alpha proteobacterium clone } \\
\text { MKC26 (EF173357) }\end{array}$ & FJ609341-FJ609343 & $91-98$ & 3 & - & - \\
\hline & $\begin{array}{l}\text { Uncultured Rhodospirillaceae bacterium } \\
\text { clone Amb 16S } 1106 \text { (EF018478) }\end{array}$ & FJ609344 & 93 & 1 & - & - \\
\hline \multirow[t]{4}{*}{$\begin{array}{l}\text { Xanthomonadaceae } \\
(\gamma)\end{array}$} & $\begin{array}{l}\text { Gamma proteobacterium RIB 1-20 } \\
\text { (EF626688) }\end{array}$ & FJ609377 & - & - & 99 & 2 \\
\hline & $\begin{array}{l}\text { Uncultured bacterium clone 010B-A05 } \\
\text { (AY661995) }\end{array}$ & FJ609382 & - & - & 92 & 1 \\
\hline & Luteimonas sp. Q-1 (AB246805) & FJ609383 & - & - & 96 & 1 \\
\hline & Luteimonas sp. CHNTR31 (DQ337595) & FJ626789 & - & - & 98 & 1 \\
\hline $\begin{array}{l}\text { Xanthomonadaceae; } \\
\text { Cibimonas }(\gamma)\end{array}$ & $\begin{array}{l}\text { Uncultured beta proteobacterium clone } \\
\text { 100M2_E5 (DQ514071) }\end{array}$ & FJ609378 & - & - & 92 & 1 \\
\hline \multirow[t]{3}{*}{$\begin{array}{r}\text { Xanthomonadaceae; } \\
\text { Rhodanobacter }(\gamma)\end{array}$} & $\begin{array}{l}\text { Uncultured bacterium clone IYF16 } \\
\text { (DQ984577) }\end{array}$ & FJ591135 & 96 & 2 & - & - \\
\hline & $\begin{array}{l}\text { Rhodanobacter lindaniclasticus, strain: } \\
\text { Gsoil } 3028 \text { (AB245366) }\end{array}$ & FJ591137 & 100 & 1 & - & - \\
\hline & $\begin{array}{l}\text { Uncultured bacterium clone 2B25 } \\
\text { (EU528240) }\end{array}$ & FJ591136 & 92 & 1 & - & - \\
\hline Total clones & & & & 70 & & 49 \\
\hline
\end{tabular}

sediment leads to a reduction of the estrogenic effect of the sediment (de Weert et al. 2008), as formed nitrononylphenol metabolites are less toxic $(85 \%$ less) than NP (Kammann et al. 2009); (Zhang et al. 2009)
Molecular analyses showed the presence of ammoniumoxidizing species Nitrosomonas eutropha and N. eutropha C91. They can be responsible for oxidation of the ammonium to $\mathrm{NO}_{2}{ }^{-}$, which is attached to the phenolic ring 
of NP. The sequences of $N$. eutropha C91 are closely related to the sequence of Nitrosomonas europaea (Koops et al. 1991). $N$. europaea is a strain that oxidizes nonsubstituted alkanes (Hyman et al. 1988) and is able to cooxidize aromatic compounds in the presence of ammonium (Keener and Arp 1994). In our batches, the formed nitrononylphenol was further degraded. As $N$. europaea has not been described to catalyze ring fission of aromatic compounds, this indicates that these organisms are not involved in the degradation of the aromatic ring in our experiments. If Nitrosomonas species form the nitrononylphenol but are not able to cleave the aromatic ring structure, other species must be involved in further biodegradation of the nitro-nonylphenol. Both clone libraries of the batches cultured with $11 \mu \mathrm{M}$ or $1 \mathrm{mM}$ NP contain sequences of species related to $B$. proteobacterium $\mathrm{C} 14$ JRPA-2007 (95-99\% similarity). B. proteobacterium C14 JRPA-2007 belongs to the Alcaligenes genus. The Alcaligenes genus contains species able to degrade ortho-nitrophenol (Xiao et al. 2007). Other strains, which are related to nitro-phenol degradation that is a comparable structure as the nitro-phenol part in our in nitro-nonylphenol metabolites, are not identified in both clone libraries.

Both clone libraries contain sequences related to nitratereducing Acidovorax sp. PD-10 and Alicycliphillus sp. R24604, which are abundantly present. Both species are closely related to $A$. avenae isolate $\mathrm{C} 1$, a nitrate-reducing, phenol-degrading bacterium (Baek et al. 2003). As our batches are aerobic, it is not likely that the nitrate-reducing strains related to Acidovorax sp. PD-10 and Alicycliphillus sp. R24604 are involved in the formation of nitrononylphenol. Furthermore, the $\mathrm{NO}_{2}$-group in the nitrononylphenol originates from ammonium instead of nitrate. Biodegradation of phenol by $A$. avenae isolate $\mathrm{C} 1$ is suggested to occur via cleavage of the ring structure (Baek et al. 2003), and this ring cleavage might also occur for NP, which is also proposed for the NP degradation by Pseudomonas species (Soares et al. 2003). The abundant presence of species related to the phenol-degrading $A$. avenae isolate $\mathrm{C} 1$ after several transfers and the presence of NP as only carbon source suggest that the biodegradation of NP occurs via the phenolic degradation pathway. Unfortunately, we have no direct evidence for this pathway, and this should be further investigated.

When tNP is degraded by Sphingomonas and Sphingobium species via ipso-hydroxylation (Gabriel et al. 2005a; Kohler et al. 2008), a shift in isomeric composition of the tNP occurs. We did not observe such a shift in the isomeric composition during the biodegradation of the mixture of branched NP isomers in the first-generation batches. Furthermore, sequences related to Sphingomonas and Sphingobium species were not identified in our batches. Both the absence of the shift in isomeric composition and the absence of strains involved in the NP degradation via ipso-hydroxylation gives a strong indication that biodegradation of NP via ipsohydroxylation in our batches is not relevant. The microorganisms identified in this study are not related to known NP-degrading bacteria such as Sphingomonas, Sphingobium, Stenotrophomonas, or Pseudomonas species (Tanghe et al. 1999; Soares et al. 2003; Ushiba et al. 2003; Gabriel et al. 2005a). This indicates that aerobic NP degradation can be performed by a wide range of microbial species and via different degradation pathways. Transfers of the bacterial population will give a different NP-degrading population as the original population in the sediment because some involved bacteria will get lost during enrichment. The untouched environment might, therefore, contain even more bacteria which are involved in the biodegradation of NP than we have identified in our cultures. The involvement of a wide range of microorganisms related to NP biodegradation enlarges the possible risk reduction of NP in the environment by biodegradation under aerobic conditions.

Acknowledgment This research was financially supported by the EU FP6 Aquaterra (project number 505428 GOCE). The authors want to thank Maarten Posthumus of the Department of Organic Chemistry of Wageningen University, The Netherlands for his help and the accurate mass weight analysis.

Open Access This article is distributed under the terms of the Creative Commons Attribution Noncommercial License which permits any noncommercial use, distribution, and reproduction in any medium, provided the original author(s) and source are credited.

\section{References}

Baek S-H, Kim K-H, Yin C-R, Jeon CO, Im W-T, Kim K-K, Lee S-T (2003) Isolation and characterization of bacteria capable of degrading phenol and reducing nitrate under low-oxygen conditions. Curr Microbiol 47:462-466

Chang BV, Yu CH, Yuan SY (2004) Degradation of nonylphenol by anaerobic microorganisms from river sediment. Chemosphere 55:493-500

Corvini PFX, Schäffer A, Schlosser D (2006a) Microbial degradation of nonylphenol and other alkylphenols - our evolving review. Appl Microbiol Biotechnol 72:223-243

Corvini PFX, Hollender J, Schumacher S, Prell J, Hommes G, Priefer U, Vinken R, Schaffer A (2006b) The degradation of alpha-quaternary nonylphenol isomers by Sphingomonas sp. strain TTNP3 involves a type II ipso-substitution mechanism. Appl Microbiol Biotechnol 70:114-122

Corvini PFX, Meesters RJW, Mundt M, Schäffer A, Schmidt B, Schröder HF, Verstraete W, Vinken R, Hollender J (2007) Contribution to the detection and identification of oxidation metabolites of nonylphenol in Sphingomonas sp. strain TTNP3. Biodegradation 18:233-245

Hesselsoe M, Jensen D, Skals K, Olesen T, Moldrup P, Roslev P, Mortensen GK, Hendriksen K (2001) Degradation of 4nonylphenol in homogeneous and nonhomogeneous mixtures of soil and sewage sludge. Environ Sci Technol 35:3695-3700

de Vries YP, Takahara Y, Ikunaga Y, Ushiba Y, Hasegawa M, Kasahara Y, Shimomura H, Hayashi S, Hirai Y, Ohta H (2001) 
Organic nutrient-dependent degradation of branched nonylphenol by Sphingomonas sp. YT isolated from river sediment samples. Microbes Environ 16:240-249

de Weert J, De la Cal A, Hvd B, Murk AJ, Langenhoff AAM, Rijnaarts HHM, Grotenhuis JTC (2008) Bioavailability and biodegradation of nonylphenol in sediment determined with chemical and bioanalysis. Environ Toxicol Chem 27:778-785

Ekelund R, Granmo A, Magnusson K, Berggren M (1993) Biodegradation of 4-nonylphenol in seawater and sediment. Environ Pollut 79:59-61

Gabriel FLP, Giger W, Guenther K, Kohler H-PE (2005a) Differential degradation of nonylphenol isomers by Sphingomonas xenophaga Bayram. Appl Environ Microbiol 71:1123-1129

Gabriel FLP, Heidlberger A, Rentsch D, Giger W, Guenther K, Kohler H-PE (2005b) A novel metabolic pathway for degradation of 4nonylphenol environmental contaminants by Sphingomonas xenophaga Bayram. J Biol Chem 22:15526-15533

Giger W, Brunner PH, Schaffner C (1984) 4-Nonylphenol in sewage sludge: accumulation of toxic metabolites from nonionic surfactants. Science 225:623-625

Heemken OP, Reincke H, Stachel B, Theobald N (2001) The occurrence of xenoestrogens in the Elbe River and the North Sea. Chemosphere 45:245-259

Hou S-G, Sun H-W, Goao Y (2006) Sorption of small metabolites of nonylphenol polyethoxylates in single and complex systems on aquatic suspended particulate matter. Chemosphere 63:31-38

Hyman MR, Murton IB, Arp DJ (1988) Interaction of ammonia monooxygenase from Nitrosomonas europaea with alkanes, alkenes, and alkynes. Appl Environ Microbiol 54:3187-3190

Kammann U, Vobach M, Wosniok W, Schäffer A, Telscher MJH (2009) Acute toxicity of 353-nonylphenol and its metabolites for zebrafish embryos. Environ Sci Pollut Res 16:227-231

Keener WK, Arp DJ (1994) Transformation of aromatic compounds by Nitrosomonas europaea. Appl Environ Microbiol 60:19141920

Kohler H-PE, Gabriel FLP, Giger W (2008) Ipso-substitution-a novel pathway for microbial metabolism of endocrine-disrupting 4-nonylphenols, 4-alkoxyphenols, and bisphenol A. Chimia 62:358-363

Koops H-P, Böttcher B, Möller U, Pommerening-Röser A (1991) Classification of eight new species of ammonia-oxidizing bacteria: Nitrosomonas communis sp. nov., Nitrosomonas ureae sp. nov., Nitrosomonas aestuarii sp. nov., Nitrosomonas marina sp. nov., Nitrosomonas nitrosa sp. nov., Nitrosomonas eutropha sp. nov., Nitrosomonas oligotropha sp. nov. J Gen Microbiol 13:1689-1699

Krooneman J, Wieringa EBA, Moore ERB, Gerritse J, Prins RA, Gottschal JC (1996) Isolation of Alicaligenes sp. strain L6 at low oxygen concentrations and degradation of 3-chlorobenzoate via a pathway not involving (chloro)catechols. Appl Environ Microbiol 62:2427-2434

Lacorte S, Raldúa D, Martínez E, Navarro A, Diez S, Bayona JM, Barceló D (2006) Pilot survey of a broad range of priority pollutants in sediment and fish from the Ebro River basin (NE Spain). Environ Pollut 140:471-482

LeBlanc GA, Rider CV (2000) Embryotoxicity of the alkylphenol degradation product 4-nonylphenol to the crustacean Daphnia magna. Environ Health Perspect 108:1133-1138

Navarro A, Endo S, Gocht T, Barth JAC, Lacorte S, Barcelo D, Grathwohl P (2009) Sorption of alkylphenols on Ebro River sediments: comparing isotherms with field observations in river water and sediments. Environ Pollut 157:698-703

Petrovic M, Solé M, López de Alda MJ, Barcelo D (2002) Endocrine disruptors in sewage treatment plants, receiving river waters, and sediments: integration of chemical analysis and biological effects on feral carp. Environ Toxicol Chem 212:2146-2156

Servos MR (1999) Review of the aquatic toxicity, estrogenic responses and bioaccumulation of alkylphenols and alkylphenol polyethoxylates. Water Qual Res J Can 34:123-177

Shannon C, Weaver W (1949) The mathematical theory information. University of Illinois Press, Urbana

Snyder AS, Keith TL, Pierens SL, Snyder EM, Giesy JP (2001) Bioconcentration of nonylphenol in fathead minnows (Pimphales promelas). Chemosphere 44:1697-1702

Soares A, Guieysse B, Delgado A, Mattiasson B (2003) Aerobic biodegradation of nonylphenol by cold adapted bacteria. Biotechnol Lett 25:731-738

Stein LY, Arp DJ, Berube PM, Chain SG, Hauser L, Jetten MSM, Klotz MG, Larimer FW, Norton JM, HJMod C, Shin M, Wei X (2007) Whole-genome analysis of the ammonia-oxidizing bacterium, Nitrosomonas eutropha C91: implications for niche adaptation. Environ Microbiol 9:2993-3007

Stephanou E, Giger W (1982) Persistent organic chemicals in sewage effluents. 2. Quantitative determination of nonylphenols and nonylphenolethoxylates by glass capillary gas chromatography. Environ Sci Technol 16:800-805

Tanghe T, Dhooge W, Verstaete W (1999) Isolation of a bacterial strain able to degrade branched nonylphenol. Appl Environ Microbiol 65:746-751

Telscher MJH, Schuller U, Schmidt B, Schaffer A (2005) Occurrence of nitro metabolite of a defined nonylphenol isomer in soil/sewage sludge mixtures. Environ Sci Technol 39:7896-7900

Thiele B, Heinke V, Kleist E, Guenther K (2004) Contribution of the structural elucidation of 10 isomers of technical $p$-nonylphenol. Environ Sci Technol 38:3405-3411

Tros ME, Schraa G, Zehnder AJB (1996) Transformation of low concentrations of 3-chlorobenzoate by Pseudomonas sp. strain B13; kinetics and residual concentrations. Appl Environ Microbiol 62:437-442

Tyler CR, Jobling S, Sumpter JP (1998) Endocrine disruption in wildlife: a critical review of the evidence. Crit Rev Toxicol 28:319-361

Ushiba Y, Takahara Y, Ohta H (2003) Sphingomonas amiense sp. nov., a novel nonylphenol-degrading bacterium isolated from a river sediment. Int J Syst Evol Microbiol 53:2045-2048

Weisburg WG, Barns SM, Pelletier DA, Lane DJ (1991) 16s ribosomal DNA amplification for phylogenetic study. J Bacteriol 173:697-703

Wheeler TF, Hein JR, Latorre MR, James B (1997) Mass spectral characterization of $p$-nonylphenol isomers using high-resolution capillary GC-MS. J Chromatogr Sci 35:19-30

Xiao Y, Zhang J-J, Liu H, Zhou N-Y (2007) Molecular characterization of a novel ortho-nitrophenol catabolic gene cluster in Alcaligenes sp. Strain NyZ215. J Bacteriol 189:65876593

Yang F-X, Xu Y, Wen S (2005) Endocrine-disrupting effects of nonylphenol, bisphenol A, and p, p-DDE on Rana nigromaculata tadpoles. Bull Environ Contam Toxicol 75:1168-1175

Yu Z, Morrison M (2004) Comparisons of different hypervariable regions of $r r S$ genes for use in fingerprinting of microbial communities by PCR-denaturing gradient gel electrophoresis. Appl Environ Microbiol 70:4800-4806

Yuan SY, Yu CH, Chang BV (2004) Biodegradation of nonylphenol in river sediment. Environ Pollut 127:425-430

Zhang H, Spiteller M, Guenther K, Boehmler G, Zuehlke S (2009) Degradation of a chiral nonylphenol isomer in two agricultural soils. Environ Pollut 157:1904-1910 